\title{
Entre ser e deixar de ser: uma abordagem jurídica da transexualidade ${ }^{1}$
}

\author{
Larissa Martins de Andrade ${ }^{2}$ \\ Professora Letícia de Souza Baddauy ${ }^{3}$
}

"Foi a vida, muito mais do que o direito, que se tornou o objeto das lutas políticas, ainda que estas últimas se formulem através de afirmações de direito. 0 'direito' à vida, ao corpo, à saúde, à felicidade, à satisfação das necessidades, o 'direito', acima de todas as opressões ou 'alienações', de encontrar o que se é e tudo o que se pode ser...".

Michel Foucault

\section{Resumo}

Entre direito e vontade, diversidade e ambiente, liberdades individuais e garantias coletivas. Entre conservadorismos e perspectivas, entre possibilidades e exclusão, entre gêneros e condutas: uma discussão a respeito do universo transexual, diante de expectativas e necessidades, tanto jurídicas quanto sociais. Para que o respeito sobreponha-se ao tradicionalismo inconseqüente, para que o indivíduo possa ser e deixar de ser, para que preconceitos sejam despidos e realidades transformadas. Para que pessoas sejam reconhecidas perante um direito ainda tímido, antiquado, tradicional. A fim de exercitar a cidadania, a igualdade, a justiça social. Sem nenhum porém, sem nenhuma segregação. A partir da questão particular dos transexuais, a possibilidade de repensar a construção sexual excludente, 0 discurso jurídico edificado na heteronormatividade, o saber médico ditador da normalidade, enfim, todos os mecanismos que legitimam a supressão de determinadas condutas. Um convite a novas reflexões, a fim de tornar o outro possível, a fim de tornar o outro verdade.

Palavras-Chave: Transexuais; Dignidade da pessoa humana; Registro civil; Bioética.

\section{Introdução}

Diante da necessidade de posturas mais tolerantes, impulsionadas por um direito mais humano e atual; diante da urgência de esclarecimentos a respeito da diversidade sexual, a fim de evitar comportamentos de ódio e exclusão; pela indispensabilidade de novas perspectivas frente às necessidades dos indivíduos, dentre outras, são as razões pela qual o

\footnotetext{
${ }^{1}$ Este artigo baseou-se no Trabalho de Conclusão de Curso por mim apresentado, em Direito, na Universidade Estadual de Londrina, sob a orientação da Professora Letícia de Souza Baddauy.

2 Aluna do 5o ano do curso de direito na Universidade Estadual de Londrina

${ }^{3}$ Advogada. Professora de Direito Processual Civil na Universidade Estadual de Londrina e na Escola da Magistratura do Paraná. Mestre em Direito Processual Civil.
} 
presente estudo objetiva abordar as questões que envolvem a trajetória dos transexuais em seus mais amplos aspectos.

Desde o esclarecimento e conceituação do tema, através da crítica ao discurso médico-legal, problematizando esses poderes e questionando suas verdades, até a análise de legislações e jurisprudência, a fim de discutir uma ordem de exclusão, deliberada e injustificadamente posta.

Aqui, a preocupação consiste em "valorizar o sujeito como ser humano e em salvaguardar sua dignidade, colocando o indivíduo como centro, como principal destinatário da ordem jurídica" (SZANIAWSKI, 1998, p 25).

Já que os sujeitos são plurais, já que as manifestações de sexo e de gênero são e podem ser muitas: por uma desconstrução do comportamento legítimo, válido, "natural" para além do universo heterossexual.

Como, de forma brilhante, argumentou Berenice Bento $(2006$, p. 22):

As travestis, as drag queens, os gays, as lésbicas, os drag kings, os transexuais têm sido objeto de estudo e intervenção de um saber que se orienta pela medicalização das condutas. No momento em que se quebra a determinação natural das condutas, também se põe em xeque 0 olhar que analisa os deslocamentos enquanto sintomas de identidades pervertidas, transtornadas e psicóticas. A radicalização da desnaturalização das identidades, iniciadas pelos estudos e políticas feministas, apontará que a identidade de gênero, as sexualidades, as subjetividades só apresentam um correspondência com o corpo quando é a heteronormatividade que orienta 0 olhar.

Por outros olhares, por novas quebras. Para que o legítimo seja contestado, repensado, analisado. Para que a multiplicidade e a pluralidade sejam. Não toleradas, mas vividas. Pelo espaço de convivência, pela plenitude de existência.

A fim de apontar os limites das categorias construídas socialmente para posicionar os sujeitos, contradizendo a possibilidade de procriação como pressuposto fundamental das relações matrimoniais; com a intenção de reestruturar as idéias de gênero, e a partir do que identificá-los. 


\section{Da noção de transexualidade}

\section{Considerações preliminares}

Diversas podem ser as perspectivas e conhecimentos que dizem ou explicam o transexual. Importa esclarecer que, no presente artigo, não farei uso dos vocábulos médicolegais comumente encontrados nas pesquisas sobre o tema, - "síndrome do transexualismo", "anomalias sexuais", "distúrbios da sexualidade" - por acreditar que os mesmos reforçam "as formas idealizadas dos gêneros e geram hierarquia e exclusão" (BENTO, 2006, p.94), objetivos completamente contrários ao presente estudo.

Veja-se, por exemplo, o entendimento médico, formalizado pelo Conselho Federal de Medicina: "Considerando ser o paciente transexual portador de desvio psicológico permanente de identidade sexual, com rejeição do fenótipo e tendência à auto-mutilação e ou auto - extermínio".

Quanto à questão de terminologia, é importante ressaltar que os termos usados para descrever pessoas transexuais sempre se referem ao gênero-alvo. Assim, a mulher transexual, por exemplo, teve sua origem biológica masculina e optou por transformações que a caracterizassem no sexo feminino. Entretanto, ainda há textos que ignoram, na nomenclatura, o gênero-alvo e insistem na referência ao sexo biológico, em postura ultrapassada e um tanto quanto desrespeitosa.

À parte essas definições, encontram-se explicações menos ofensivas e talvez mais esclarecedoras sobre 0 assunto.

Partir do conceito de transexualidade como conflito identitário, e não como enfermidade. Já que, supostamente, fundamentando-se na diferença sexual, pressupõe-se uma concordância entre gênero, sexualidade e corpo. 0 que, de fato, não existe.

\footnotetext{
Mulheres que não querem ser mães, mulheres que amam mulheres, homens e mulheres biológicos que reconstroem seus corpos e lutam pelo reconhecimento de suas identidades de gênero e tantos outros deslocamentos que nos revelam a ficção de pensar que os múltiplos desejos que nos constituem são oriundos de nossas estruturas biológicas e hormonais (BENTO, 2006, p.13).
}

Do conhecer-se ao aceitar-se, das relações familiares ao ambiente social - "Sempre disse aos meus filhos que ao crescer poderiam fazer o que quisessem, mas nunca sonhei que 
um deles ia querer ser uma mulher" 4- da luta para "pertencer" aos entraves burocráticos, do discurso médico ao saber jurídico, enfim, pela possibilidade de desmistificar e familiarizar a luta trans, e, por conseqüência, todas as manifestações por reconhecimento e igualdade social.

[...] corpos pré-operados, pós-operados, hormonizados, depilados, retocados, siliconados, maquiados. Corpos inconclusos, desfeitos e refeitos, arquivos vivos de histórias de exclusão. Corpos que embaralham as fronteiras entre 0 natural e 0 artificial, entre o real e o fictício, e que denunciam, implícita ou explicitamente, que as normas de gênero não conseguem um consenso absoluto na vida social.

Em silêncio, as cicatrizes que marcam os corpos transexuais falam, gritam, desordenam a ordem naturalizada dos gêneros e dramatizam perguntas [...]: existem homens e mulheres de verdade? 0 corpo é o delimitador das fronteiras entre gêneros? 0 natural é o real? Existe um ponto de fixação e delimitação entre 0 real e o fictício? Se a verdade está no corpo, os sujeitos que não se reconhecem em seus corpos generificados vivem uma mentira, estão fora da realidade? (BENTO, 2006, p.19)

Perguntas urgentes, fundamentais. Nem de longe recentes. Todavia ignoradas. Quando o compreender faz-se imperativo para quaisquer possibilidades de mudanças. Já que o discurso médico-jurídico goza de imperatividade. Fundamentada em quê? Ou em quem, para quem? Porque muito já se debateu a respeito dos direitos humanos, das minorias, da bioética, da ética. Mas quanto mudou, quanto precisa mudar?

As histórias se repetem, e também a resistência. 0 acesso aos dados trans são difíceis, mascarados. Pesquisas apontam para números inconclusos: "Já são cerca de 30.000 a 40.000 mulheres transexuais pós-operadas que vivem nos Estados Unidos" ${ }^{5}$. E quanto aos não-operados, aos transexuais masculinos, aos tantos outros países? Difíceis respostas.

Outra consideração essencial é a da violência sofrida pelas minorias sexuais. Pesquisa realizada pela Associação da Parada do Orgulho GLBT (Gays, Lésbicas, Bissexuais e Transexuais) de São Paulo, em $2007^{6}$, aponta para o dado alarmante de que $70 \%$ dos entrevistados já haviam sido vítimas de discriminação - quase metade dos agressores eram

\footnotetext{
${ }^{4}$ EVELYN, Just. Mom, I need to be a girl. Disponível em: http://ai.eecs.umich.edu/people/conway/TS/Evelyn/ Portuguese/INTRO.PT.html. Acesso em: 19. maio. 2008

${ }^{5}$ Conway, Lynn. Disponível em: http://ai.eecs.umich.edu/people/conway/TSsuccesses/TSsuccessesPortuguese.html. Acesso em: 20.maio.2008.

${ }^{6}$ Associação da Parada do Orgulho GLBT Disponível em: http://www.agenciabrasil.gov.br/ noticias/2007/03/28/materia.2007-03-28.8190554340/view. Acesso em: 20.maio.2008.
} 
pessoas desconhecidas, e o fizeram em locais públicos. Dentro do grupo GLBT, as transexuais e travestis eram as maiores vítimas do preconceito.

Cultura de ódio, comportamentos marcados pela intolerância, convencionalismos despropositados. E o Direito - indiferente ou promissor, suficiente ou à parte, promessa ou crendice?

Da diversidade sexual

Muitas são e podem ser as manifestações das sexualidades dos indivíduos, abrangendo aspectos de identidade de gênero, subjetividades, desejos, enfim, uma construção íntima e infinitamente plural.

No que se convencionou chamar "orientação sexual", de maneira simples, abrangendo única e tão somente a manifestação do desejo: a quem se dirige, sobre quem se projeta.

Nessa perspectiva, os comportamentos foram rotulados em homossexuais, quando indivíduos sentem-se atraídos por pessoas do mesmo sexo; heterossexuais, quando a atração direciona-se ao sexo oposto; e bissexuais, atraídos por ambos os sexos, entre outros.

Entretanto, a transexualidade é questão ligada à identidade de gênero - considerase transexual o indivíduo que não encontra correspondência com o seu sexo de nascimento, identificando-se totalmente com o sexo oposto e assumindo características deste, querendo assim tornar-se e permanecer.

Ainda nas questões de identidade de gênero, também podemos mencionar 0 comportamento travesti, muitas vezes confundido com o transexual, que implica tão somente em uma inclinação ao uso de trajes típicos do sexo oposto, associado à excitação erótica, ao fetiche, sem implicar em qualquer descontentamento com o sexo anatômico.

A problemática da identidade sexual de alguém é muito mais ampla do que seu simples sexo morfológico. Deve-se, pois, considerar o comportamento psíquico que 0 indivíduo tem diante de seu próprio sexo. Daí resulta que o sexo compõe-se da conjunção dos aspectos físico, psíquico e comportamental da pessoa, caracterizando-se, consequentemente, seu estado sexual (SZANIAWSKI, 1998, p 35).

Nesse sentido, não há que se fazer qualquer ligação direta e necessária entre identidade de gênero e orientação sexual. Um não implica, nem tampouco depende do 
outro: são aspectos distintos, e pressuposições partem de idéias equivocadas e estereotipadas de gêneros.

Quando uma pessoa diz: 'Eu tenho um corpo equivocado, sou uma mulher aprisionada em corpo de homem', isso não significa que ser mulher seja igual a ser heterossexual. Quando a sociedade estabelece que o homem/mulher de verdade é heterossexual, deduz-se imediatamente que um homem/mulher transexual também deverá sê-lo, e são construídos dispositivos em torno dessa verdade (BENTO, 2006, p.156)

Diante desta reflexão, talvez se mostre ainda mais polêmica e difícil a luta por reconhecimento e respeito ao universo trans, tanto por ignorâncias múltiplas como construções sociais que esbarram diante de tal idéia.

$\mathrm{Se}$, quanto à aceitação das minorias, o movimento gay ainda enfrenta negações e preconceitos, tanto no universo social quanto no jurídico, os transexuais, por sua vez, enfrentam, além disso, o não-existir, o negar, o nem se quer cogitar. Afrontam, ainda, a questão da medicalização das condutas: o "desviante", o "portador de síndrome da transexualidade", a "anomalia sexual", a "neurose reacional obssessivo-compulsiva". Como se não bastasse um saber médico que os exclui, resiste um saber jurídico tradicional, ditador de verdades, que a eles resiste.

Da identificação transexual

Entender e esclarecer alguns aspectos da transexualidade não implica em pretensões absurdas de classificar e delimitar os indivíduos que assim se identificam. M esmo porque não há um único comportamento transexual. Antes de serem transexuais: são seres humanos, com suas individualidades, gostos, preferências, opiniões, às vezes completamente divergentes e distintas. Como fato é que não há uma unanimidade heterossexual, nem tampouco uma unanimidade gay ou lésbica, não há, também, um protótipo transexual.

Estamos diante de diferentes histórias, crenças, desejos. Uma transexual sueca que fez a cirurgia de redesignação aos 73 anos: 'Quero morrer como uma mulher'; uma transexual, Patrícia, que afirma 'detestar gays'; transexuais que fundamentam seus sonhos a partir da cirurgia de mudança de sexo, outros que não se importam; mulheres transexuais 
lésbicas, homens transexuais gays; transexuais que desejam um relacionamento heterossexual estável, convencional, familiar; enfim, infinitas pluralidades.

Não existe uma 'identidade transexual', mas posições de identidade organizadas através de uma complexa rede de identificações que se efetiva mediante movimentos de negação e afirmação aos modelos disponibilizados socialmente para se definir o que seja um homem/mulher 'de verdade' (BENTO, 2006, p. 207)

Há ainda que se considerar a construção social dos gêneros. Para Judith Butler (BENTO, 2006. p. 86):

[...] 0 gênero não está passivamente inscrito sobre o corpo. Os atores estão sempre no cenário, dentro dos mesmos termos da performance. Assim como uma trama pode ser representada de múltiplas formas, e assim com uma obra requer, ao mesmo tempo, texto e interpretação, o corpo sexuado faz sua parte em espaços culturalmente definidos e leva adiante as interpretações dentro dos limites já existentes.

Nesse sentido, como sugeriu Beatriz Preciado (2002), o comportamento transexual põe em xeque as ideologias de gênero e passa a negociar constantemente com as mesmas, em um processo de reconstrução e reinvenção do próprio corpo. A experiência transexual nos diz que o corpo-sexuado que Ihe foi atribuído não serve para lhe conferir sentido.

Patrícia: Eu estou indo às igrejas, aí eu já falo de cara: 'Oh, sou operada, sou mulher, está aqui no documento... ' Eu estou mentindo, mas, se eu não fizer isso, eles vão começar a dizer: 'Ah, nós vamos fazer uma terapia com você, aí você logo vai ver que vai mudar de idéia, vai tirar essas roupas e vai virar homem'. Então, eu falo que já sou operada para eles não pegarem no meu pé. Porque, se já fez a cirurgia, não tem mais jeito (BENTO, 2006, p.64).

No relato dessa transexual, evidente fica a 'negociação' com o ambiente social, para enfim ver respeitadas suas escolhas, seu comportamento feminino. E o Direito é o dispositivo para tanto. O significado que os documentos, com suas identificações de nome e sexo, passam a ter para um transexual é de amplitude muito maior do que o trivial: é mecanismo de imposição de verdades, com conseqüente obrigação de deferência e consideração.

Independentemente da realização da cirurgia da redesignação do estado sexual questão, ainda hoje, de infeliz importância para o saber médico-legal, que a tem como 
pressuposto de validade para o reconhecimento dos direitos básicos dos transexuais - há que se compreender e acatar a forma como cada qual se identifica, e a construção dessa identificação.

Se para muitos transexuais o direito de realizar as cirurgias não deve estar vinculado ao poder médico, para outros, a mudança dos documentos tampouco pode estar condicionada à realização das cirurgias. Nesses casos, o documento com o nome próprio de acordo com o gênero identificado, as mudanças corporais pelo uso dos hormônios e algumas técnicas para conseguir uma estética considerada apropriada são transformações suficientes para lhes garantir um sentido de identidade. Para eles, a cirurgia de transgenitalização não tem importância [...]. A identidade legal de gênero, então, é a principal reivindicação [...] (BENTO, 2006, p.233).

De tal modo, a ciência em questão não pode, nem deve, jamais "se perder na polêmica estéril das posturas dogmáticas e na defesa de posições pessoais que nada acrescentam, nada constroem e, quase sempre, acabam desconsiderando a pessoa humana" (SZANIAWSKI, 1998, p. 13).

Diante de todo constrangimento, humilhação, exclusão sofridos, não só pelos transexuais, mas por todas as minorias que, de forma deprimente, ainda são privadas das "vantagens das propostas normativas sempre elaboradas com base em parâmetros ideais" (SZANIAWSKI, 1998, p. 13), faz-se imprescindível repensar e reestruturar as normas e mecanismos jurídicos, a fim de que seja o direito propulsor de mudanças comportamentais, e não, como sempre, aquele que espera inerte pelo caminho inverso.

Questões pertinentes, que abordam desde a autorização da cirurgia de redesignação do estado sexual (propostas médicas), a mudança no registro civil, o casamento, a adoção, a filiação, enfim, as possibilidades do relacionar-se enquanto indivíduo social, e as implicações que as recusas podem causar.

Pela possibilidade de existir. Pela chance de ser, em meio aos demais.

Kátia: Na escola, quando me chamavam de veado ou de macho-fêmea, eu chorava, me afastava de todo mundo, não saía para o recreio. Eu só tenho a 3a série completa. Eu parei em $96 . .$. Eu parei de estudar no meio da 4a série. Notas boas... Por causa desse preconceito que eu não agüentava. Não agüentei o preconceito de me chamarem de macho-fêmea, de veado, de travesti, essas coisas todas (BENTO, 2006, p.208). 
O quanto poderia o direito diante disso? Ou melhor, o quanto quer a realidade jurídica ser alterada a fim de abranger as múltiplas formas de existir?

\section{Dos aspectos jurídicos}

Depois de enfrentar as idéias simplistas e pré-concebidas das manifestações sexuais; depois de democratizar a dignidade da pessoa humana; depois de respeitadas as diferenças e particularidades dos indivíduos: só então poderemos repensar a ordem que sustenta esses valores, questionar "todos os temas que o direito engessado e mumificado encara, desconfiado e cauteloso - em manifesta atitude escapista e elitizada", questionar "uma ciência que não mais consegue se justificar pelo mero invocar de normas, quando dissociada da dimensão maior do ser humano, bem máximo a ser protegido pelo direito" (SZANIAWSKI, 1998, p 94).

Aqui, a discussão envolve direitos da personalidade, direito ao próprio corpo, à integridade física e psíquica, à privacidade, à identidade pessoal, à saúde: à existência. Assuntos tão discutidos e de notória importância. Aliás, valor este já sedimentado em declarações, constituições, conferências, pactos. Mas ainda negados a alguns, a muitos.

Quando alguns passos são motivadores, outros escandalosos. "Sus começa esse ano inscrição para cirurgias de mudança de sexo", ou a decisão inédita no Rio de Janeiro: "Transexual consegue mudar registro sem cirurgia"; em contrapartida: "Gâmbia: presidente diz que irá matar todos os homossexuais", "Ataques de homofobia em São Paulo fizeram mais uma vítima no último sábado". Quais são as perspectivas para alterar o muito que ainda há de absurdo nessa realidade?

Analisaremos os dispositivos que são capazes de garantir e assegurar a igualdade de condições e oportunidades jurídicas aos transexuais, e, consequentemente, a todas as minorias que ainda se vêem privadas de direitos básicos, essenciais. Além disso: minorias expostas a violências - nos olhares, nos gestos, nos discursos - insistentes, reincidentes, humilhantes.

Apesar da 'timidez' e insensibilidade legislativa em regulamentar 0 assunto resumida a algumas tentativas isoladas e frustradas - fundamentação jurídica para 
possibilitar as diferentes manifestações sexuais (aqui, especificamente, a transexualidade), existem e podem ser suficientes.

\section{Fundamentos legais}

\section{Declaração universal dos direitos humanos}

Se, em 1948, a Assembléia Geral das Nações Unidas proclamava e o Brasil assinava, na mesma data, declaração que reconhecia a dignidade inerente a todos os membros da família humana e de seus direitos iguais e inalienáveis, como fundamento da liberdade, da justiça e da paz no mundo, e dispunha:

Artigo I - Todas as pessoas nascem livres e iguais em dignidade e direitos. São dotadas de razão e consciência e devem agir em relação umas às outras com espírito de fraternidade.

Artigo II - Toda pessoa tem capacidade para gozar os direitos e as liberdades estabelecidos nesta Declaração, sem distinção de qualquer espécie, seja de raça, cor, sexo, língua, religião, opinião política ou de outra natureza, origem nacional ou social, riqueza, nascimento, ou qualquer outra condição.

Artigo III - Toda pessoa tem direito à vida, à liberdade e à segurança pessoal [... ].

Artigo $\mathbf{~ V I ~ - ~ T o d a ~ p e s s o a ~ t e m ~ o ~ d i r e i t o ~ d e ~ s e r , ~ e m ~ t o d o s ~ o s ~ l u g a r e s , ~ r e c o n h e c i d a ~}$ como pessoa perante a lei.

Artigo VII - Todos são iguais perante a lei e têm direito, sem qualquer distinção, a igual proteção da lei. Todos têm direito a igual proteção contra qualquer discriminação que viole a presente Declaração e contra qualquer incitamento a tal discriminação [...].

Artigo XII - Ninguém será sujeito a interferências na sua vida privada, na sua família, no seu lar, ou na sua correspondência, nem a ataques à sua honra e reputação. Toda pessoa tem direito à proteção da lei contra tais interferências ou ataques.

De forma suficiente e clara, eqüitativa e sensível, a Declaração Universal dos Direitos Humanos já antecipa uma perspectiva necessária e indispensável para uma nova convivência, democrática e harmônica, distante dos crimes e posturas de racismo e ódio que marcaram a humanidade.

Ainda que de forma geral, através desses parâmetros, já não há como entender os argumentos que negam direitos, que excluem, oprimem. Não há como justificar um ordenamento jurídico que, em regra, nega-se a deferir pedidos de mudança de nome aos transexuais, ou então, quando o fazem, mantém o sexo anterior à mudança nos registros. 
Um ordenamento que, preso a rigorismos e preconceitos expõe, de forma vulgar e explícita, pessoas às situações das mais vexatórias e humilhantes.

Todavia, além disso, temos uma Constituição Federal.

\section{Constituição da República Federativa do Brasil}

Inegável é que a ausência de normas específicas, direcionadas às questões dos transexuais - como mudança no registro civil, matrimônio, procriação - dificultam a prestação da tutela jurisdicional. Entretanto, não se admite a não-aplicação do direito, de forma justa e razoável, com alegações dessa natureza.

Caso queiram, a Constituição Federal oferece-nos dispositivos suficientes para tratar a todos os indivíduos, sem exclusão dos transexuais, homossexuais e outras minorias, de forma semelhante, sem negação ou exclusão.

Artigo 10 A República Federativa do Brasil [...] tem como fundamentos:

II - a cidadania;

III - a dignidade da pessoa humana [...].

Artigo 3o Constituem objetivos fundamentais da República Federativa do Brasil:

[...]

IV - promover o bem de todos, sem preconceitos de origem, raça, sexo, cor, idade e quaisquer outras formas de discriminação.

Artigo 5o. Todos são iguais perante a lei, sem distinção de qualquer natureza, garantindo-se aos brasileiros e aos estrangeiros residentes no País a inviolabilidade do direito à vida, à liberdade, à igualdade, à segurança [...].

Artigo 196. A saúde é direito de todos e dever do Estado [...].

Artigo 226. A família, base da sociedade, tem especial proteção do Estado.

Diante desses mecanismos de proteção à dignidade da pessoa humana, diante da igualdade como valor primeiro e pressuposto mínimo para maiores garantias, diante da pluralidade e infinidade de comportamentos, a reflexão que se apresenta é por que, e baseado em que não se efetivam mudanças a fim de promover tudo aquilo que nossa Constituição elegeu como essencial. 


\section{Jurisprudência}

Pretendo, no presente tópico, e dando continuidade aos fundamentos legais acerca do tema, discutir julgados, por vezes promissores, outras decepcionantes, questionando suas prerrogativas e argumentações.

\section{Tribunal de Justiça do Estado de São Paulo}

Registro Civil. Pedido de alteração do nome e do sexo formulado por transexual primário operado. Cuida-se de ação de conhecimento tendo por objeto a alteração do assento de nascimento do autor, tanto em relação ao nome como ao sexo. Fundamenta-se no fato de ser transexual [...]. A sentença desacolheu a pretensão apoiando-se na inexistência de erro na lavratura do assento de nascimento, impondo ao autor 0 ônus da sucumbência [...]. Apelou 0 autor, sustentando que a utilização do seu nome 0 expõe a situações embaraçosas [...]. Recebido o recurso, 0 Ministério Público, em contra-razões, admitiu o provimento parcial apenas para deferir a alteração do nome, mantida, no entanto, a indicação do sexo masculino. A Procuradoria Geral de Justiça, através do parecer da Dra. Leila Mara Ramacciotti Vasconcellos, opinou pelo provimento integral do recurso, alterando-se o nome e 0 sexo do assento de nascimento do autor. ${ }^{7}$

De forma muito breve, essa decisão nos remete a infeliz postura assumida, em regra, pelos juízos de primeiro grau.

A argumentação do juiz, embasada, aparentemente, na Lei n. 6.015, de 31 de dezembro de 1973, que dispõe sobre os registros públicos, além de completamente descabida, desconsidera todos os aspectos humanos que envolvem a questão. Em momento algum o fato foi tido como "erro na lavratura do assento de nascimento": é evidente que a hipótese não é esta. Trata-se de uma pessoa com identificação social feminina e um registro de nascimento masculino. Não há dúvidas de que infinitas situações embaraçosas podem advir dessa discordância.

Em brilhante arguição, a juíza da 8a Vara de Família, do Rio de Janeiro, no caso internacionalmente conhecido de Roberta Close, sustentou:

Manter-se um ser amorfo, por um lado mulher, psíquica e anatomicamente reajustada, e por outro lado homem, juridicamente, em nada contribuiria para a preservação da ordem social e da moral, parecendo-nos, ao contrário, um fator de instabilidade para todos aqueles que com ela contactassem, quer nas relações

\footnotetext{
${ }^{7}$ BRASIL. Tribunal de Justiça do Estado de São Paulo (5. Câmara). Civil. Apelação Cível no 165.157.4/5. Apelante: Adão Lucimar. Apelado: Ministério Público. Relator: Desembargador Boris Kauffmann. São Paulo, 22 de março de 2001.
} 
pessoais, sociais e profissionais, além de constituir solução amarga, destrutiva, incompatível com a vida ${ }^{8}$.

\section{Tribunal de Justiça do Rio Grande do Sul}

Com uma perspectiva mais permissiva, todavia ainda condicionada: o Tribunal em questão autoriza a mudança do nome e sexo no registro civil, porém, a cirurgia de redesignação do estado sexual ainda representa requisito de grande repercussão para 0 pedido.

Trata-se da irresignação do Ministério Público com a referida sentença que julgou procedente a ação de retificação de registro civil movida por Sandro M. E., determinando a retificação, no assento de nascimento, do seu nome para Márcia e do seu sexo, de masculino para feminino. Sustenta o Ministério Público que, ainda que deva ser preservada a intimidade do requerente, deve ser resguardado 0 interesse público, assegurando-se a publicidade, segurança jurídica e eficácia do registro. Diz que eventual decisão que vede 0 fornecimento de certidões sobre a situação anterior do requerente possibilita a ocorrência de danos a terceiros de boa-fé [...]. Com efeito, a questão posta nos autos diz com o direito da pessoa à alteração de nome e de sexo, que foi formulado em razão da condição de transexual, já tendo feito a cirurgia de adequação ao gênero a que, psicológica e socialmente, adota, que é o feminino, com o direito à sua privacidade e com 0 respeito às disposições registrais. No entanto, merece reparo a sentença ao determinar a alteração, vedando "por ocasião do fornecimento de certidões, referência a sua situação anterior". Observo que deve ser resguardada a boa-fé de terceiros, mediante a averbação à margem do termo, como postulado pelo diligente órgão ministerial de primeiro grau, nos moldes análogos ao que dispõe 0 art. 19, § 30 da Lei de Registros Públicos. Ou seja, deve constar na certidão apenas que existe averbação decorrente de determinação judicial alterando o registro, mas sem fazer qualquer menção à razão determinante dessa alteração do registro civil, nem acerca de quais alterações foram procedidas, resguardando-se, desta forma, tanto a publicidade dos registros, como também do direito de intimidade do requerente. Assim sendo, nenhuma informação ou certidão poderá ser dada a terceiros, relativamente à alterações nas certidões de registro civil, salvo ao próprio interessado ou no atendimento de requisição judicial $[. . .]^{9}$.

Com uma solução de média satisfação, o Tribunal do Rio Grande do Sul, diante da apelação do M inistério Público, de infeliz fundamentação, visto que, como defensor do bem estar comum, deveria ponderar que, entre a "boa-fé de terceiros", em situação claramente futura e hipotética, e a dignidade da pessoa humana, à integridade física e moral, o direito à identidade pessoal, não há, nem de longe, comparação, quiçá a prevalência dos interesses

8 Mudança de nome. Disponível em: http://conjur.estadao.com.br/static/text/25342,2. Acesso em: 13.junho. 2008

${ }^{9}$ BRASIL. Tribunal de Justiça do Rio Grande do Sul .Civil. Apelação Cível no 70018911 594. Apelante: Ministério Púlbico. Apelado: Sandro Márcio Eliodoro. Relator: Desembargador Sérgio Ferando de Vasconcelos. Guaíba, 25 de abril de 2007. 
de terceiros. Média satisfação, já que adotou a averbação à margem do termo, mas mantendo sigilo no que diz respeito aos motivos da mesma, e condicionando sua obtenção à requisição judicial.

\section{Tribunal de Justiça do Estado do Rio de Janeiro}

A. P. R. V. propõe a presente ação objetivando a retificação do registro civil para mudança de prenome e sexo [...] Diz a autora que desde a sua tenra idade apresentava comportamento diferenciado das outras meninas, engajando-se em atividades e brincadeiras masculinas, bem como mantendo comportamento de igual teor [...] Em torno de seus 20 anos, procurou tratamento para o transtorno que a atingia no Hospital das Clínicas da USP, no Instituto de Psiquiatria onde funciona o projeto sexualidade, obtendo o diagnóstico de transexualismo [...] Afirma mais que atualmente faz uso de testosterona, realizou cirurgia para a retirada das mamas, tendo agora um peitoral semelhante ao masculino, bem como fez a ablação de seu aparelho reprodutor, não mais possuindo a capacidade de produzir hormônios femininos que lhe concediam as características femininas secundárias. Porém, não deseja se submeter a faloplastia (cirurgia para a construção de um pênis) enquanto 0 procedimento estiver em caráter experimental, sem garantia de satisfação plena. Aduz, por fim, que no meio social é conhecido como G. e a permanência do prenome feminino the causa impossibilidade de uma vida livre de constrangimentos e discriminações [...] Não posso deixar de registrar que as cirurgias a que se submeteu a autora não alteraram o seu código genético, apenas a aparência da mesma que se definiu com 0 uso de testosterona (hormônio masculino), adequando-se em parte o corpo à sua mente. Mas, como o Direito deve acompanhar as mudanças sociais e sua função primordial é a de ditar a Justiça, creio que a demanda deva prosperar na sua integralidade ${ }^{10}$.

Em postura digna de aplausos, combinada com belíssima fundamentação, 0 Tribunal de Justiça do Rio de Janeiro, nesse caso, expôs o drama transexual e mostrou alternativas viáveis e atuais para as relações jurídicas, e como é possível dizer o direito de forma justa e fiel à dignidade da pessoa humana, apesar da resistência ao assunto.

[...] o juiz não pode mostrar-se alheio às transformações sociais, jurídicas e científicas. Por isso a vontade da lei não deve ser investigada somente em relação à época em que nasceu o preceito, mas sim tendo em conta o momento de sua aplicação. 0 magistrado adapta o texto da lei às evoluções sofridas pela vida, da qual, em última consideração, o Direito é forma. Daí o poder dele ajustá-la a situações que não foram imaginadas na hora remota de seu nascimento (ÁSUA, 1942, p. 103).

\footnotetext{
10 Transexual consegue mudar registro sem cirurgia. Disponível em: http://jus2.uol.com.br/pecas/texto.asp?id=847. Acesso em: 24. maio. 2008.
} 
Posturas jurídicas mais humanas e reais são obviamente possíveis. Ainda, apesar da resistência legislativa para regulamentar tais assuntos, envoltos em preconceitos e conservadorismos, evidente fica a flexibilidade do direito em possibilitar, baseado em pressupostos fundamentais, vida digna a todos os indivíduos.

\section{Do direito à família}

Questionados os aspectos ideológicos e jurídicos, com conseqüente valorização do ser enquanto humano, resta-nos, ainda, analisar as implicações decorrentes da mudança transexual no universo jurídico, especialmente aquelas que se relacionam com a vida civil. Notadamente, o casamento demanda maiores reflexões.

Qual é a real condição, para o mundo do direito, da pessoa que se submeteu a cirurgia de redesignação sexual? Se concedida a mudança nos registros, de forma plena e satisfatória (entende-se: sem qualquer averbação ou declaração que remeta a condição anterior), conseguirá o transexual desfrutar de todas as prerrogativas e direitos inerentes ao sexo do qual, agora, pertence? Ou será o direito seletivo e discriminatório, negando-lhe alguns benefícios, já que, ainda, transexual?

Dessa reflexão, múltiplas são as implicações: matrimônio, filiação, licença maternidade, aposentadoria, cargos exclusivos a determinado gênero. Para algumas, ainda que de forma abstrata, o universo jurídico é capaz de proporcionar soluções satisfatórias. Para outras, como a filiação e o direito de procriação, muito nos falta refletir e normatizar. Para que todos tenham o direito de ser. Ou deixar de ser.

\section{Do casamento}

Importante ressaltar que, nos julgamentos, nada se fala a respeito da possibilidade ou não da ocorrência de casamento. E as reflexões surgem a partir do momento em que se contempla a hipótese de alguém que, desconhecendo a condição de transexual de seu parceiro, tendo-o como pertencente ao sexo registral, venha com ele a contrair matrimônio.

A primeira pergunta que se impõe é se a cirurgia possui o efeito de mudar o sexo, isto é, se transforma efetivamente o homem em mulher ou a mulher em homem. Sendo a resposta afirmativa, nenhuma dúvida pairaria sobre a existência, a validade e a higidez do casamento, e, por conseqüência, desnecessária qualquer 
regulamentação à espécie. Porém, a resposta só pode ser negativa. A cirurgia, ainda que modifique as características anatômicas, orgânicas e aparentes do sexo, não altera o código genético do indivíduo, que corresponde às características do sexo cromossomático. Não haveria a transformação da situação biológica, mas exclusivamente a tentativa de correção de uma inaptidão psicológica. Não haveria inversão da natureza, mas mudança de uma forma de viver ${ }^{11}$.

Não seria objetivo e dever do direito, enquanto mecanismo de justiça e igualdade social, tutelar, justamente, as formas de viver? Seria a situação biológica de cada qual fundamento suficiente para justificar tratamentos díspares?

Apenas é necessário citar a "dignidade da pessoa humana" para vislumbrar o óbvio - não deveríamos, nem poderíamos ater-nos ao código genético de cada qual para excluí-los de benefícios.

Válido, então, seria o casamento de um transexual "que já tenha obtido o reconhecimento judicial de sua condição feminina" (VIEIRA, 1996, p. 255).

Além disso: nossa legislação pátria, no que diz respeito à formalização das uniões, há tempos deveria ser repensada e readaptada. Enquanto o intuito do casamento, até então, parece ser fundamentado na opção e escolha dos que o fazem, a fim de compartilhar a existência, razão não há para que a diferença dos sexos seja pressuposto fundamental para o mesmo. Inadequado e retrógrado o posicionamento contrário, já que, evidentemente, múltiplas são as manifestações dos desejos, assim como as da existência.

\section{Código civil}

Artigo 1.511. O casamento estabelece comunhão plena de vida, com base na igualdade de direitos e deveres dos cônjuges.

Artigo 1513. É defeso a qualquer pessoa, de direito público ou privado, interferir na comunhão de vida instituída pela família.

Precisa o direito, nesses parâmetros, aproximar-se da realidade da vida. Quem teria a ousadia de, diante da realidade, defender a "família legítima"? Quais seriam os pressupostos para representar a unidade familiar? Mais que isso: haveria necessidade de limitações?

${ }^{11}$ DIAS, Maria Berenice. Transexualidade e o direito de casar. Disponível em: http://www.uj.com.br/ publicacoes/doutrinas/default.asp? action=doutrina\&iddoutrina=3273. Acesso em: 15.junho.2008. 
A "comunhão de vida", contemplada pelo Código Civil ao tratar do casamento, não é requisito mais do que suficiente para reconhecer e respeitar as relações a partir daí formuladas?

A diferença dos sexos deixaria de ser condição fundamental para o matrimônio, e, consequentemente, indagações a respeito da possibilidade ou não de um transexual fazê-lo seriam dispensáveis.

Todavia, como o universo jurídico ainda não nos contemplou com esse avanço, necessidade há de encontrar mecanismos legais que possibilitem o casamento para um transexual.

Como já mencionado, uma vez reconhecida, juridicamente, a condição sexual do redesignado, não há motivos para impedi-lo de casar. Entretanto, questão relevante é a que incide no desconhecimento do outro cônjuge a respeito da condição de transexual.

Descabe argumentar que registro público possui efeito constitutivo, servindo para provar a existência e a veracidade do que está consignado. Não há como tornar pública a alteração registral levada a ef eito e acessível ao conhecimento de todos. Mesmo que qualquer alteração posterior deva ser obrigatoriamente mencionada, sob pena de responsabilidade civil e penal do serventuário, conforme expressamente preconiza a Lei dos Registros Públicos, tal regra não pode ensejar infringência ao sagrado princípio de respeito à privacidade e à identidade pessoal. Integra o restrito campo do livre arbítrio de todo e qualquer indivíduo o direito de revelar ou ocultar seu sexo real, o sexo com o qual se identifica, o sexo pelo qual optou. Entre os dois princípios, possui mais relevância o que diz com o direito à identidade, devendo ser o prevalentemente preservado ${ }^{12}$.

Assim, caso haja desconhecimento do cônjuge sobre a situação, a legislação contempla a hipótese de anulação do casamento, fundamentada em erro essencial sobre a pessoa.

Artigo 1.556. 0 casamento pode ser anulado por vício da vontade, se houver, por parte de um dos nubentes, ao consentir, erro essencial quanto à pessoa do outro. Artigo 1557. Considera-se erro essencial sobre a pessoa do outro cônjuge: I - o que diz respeito à sua identidade, sua honra e boa fama, sendo esse erro tal que o seu consentimento ulterior torne insuportável a vida em comum ao cônjuge enganado.

$[\ldots]$

12 Idem, ibdem. 
Como bem advertiu Tereza Rodrigues Vieira (1996, p. 48), "Não deve o legislador intervir, entretanto o transexual que dissimulou sua condição deverá responder por sua omissão".

Por óbvio que, quando enganado, o terceiro possa recorrer à anulação do casamento. Agora, descabido seria impedir o transexual de casar, ou obrigá-lo a revelar sua condição, como em lamentável alegação:

A fim de se evitarem os transtornos de uma ação anulatória de casamento, por erro essencial sobre a pessoa do transexual redesignado, tem-se recomendado que, por ocasião da alteração do assento de nascimento no registro civil, se faça constar, à margem do mesmo, que se trata de um indivíduo portador de status sexual redesignado, a fim de impedir que terceiro de boa-fé seja levado a erro quanto à identidade do redesignado (SZANIAWSKI, 1998, p. 25).

Surpreendente que alguns possam dar mais relevância ao terceiro (diga-se, hipotético) de boa-fé e resguardar por sua moral e consciência, quando para tanto é necessário ignorar, por completo, postulados como o direito à intimidade, à privacidade, à dignidade, à igualdade, e outros tantos (vale lembrar: com amparo constitucional).

\section{Considerações finais}

Quando a discussão ultrapassa as fronteiras da sexualidade, das individualidades, das diferenças. Porque o assunto foi e é apenas um: respeito. Respeito diante do outro, do que não se entende, ou não se conhece. Consideração pelo que não se é. Deferência diante dos homens, pelos homens.

Muito já se viu e ouviu, e também se lamentou, a respeito das posturas de ódio institucionalizado, de perseguições arbitrárias, de políticas excludentes. Mas, de forma sutil, outras nem tanto, pouco se fez pela tolerância, pouco se deu ao diferente.

Direitos humanos: por indivíduos plurais, por vontades mil, por manifestações de vida diversas. Para que não seja um só o caminho. Para que cada um, diante de si e para si, tenha possibilidades. Possibilidades de questionar seu sexo, seu desejo, sua existência. Possibilidade de tornar-se outro, de decidir se casa ou não, se tem filho ou não, se adota ou não. E manifestar suas vontades. Sem medo de ignorâncias, convencionalismos, bestialidades. Sem restrições infundadas ou limites tiranos. 
Para que as pessoas mobilizem-se e lutem mais por opções, menos por restrições. Já que cada qual sabe de si. E escolhe por si. Já que, enquanto um, distante de ferir ou agredir 0 outro, as escolhas deveriam e poderiam ser plenas.

Para que não seja o Direito dispositivo de concretização de posturas excludentes e ilógicas, não sejam os juristas multiplicadores de uma realidade patética e lamentável, não sejamos nós passivos e entorpecidos perante o absurdo.

A partir disso, ou para isso, um direito objetivo, democrático, justo. Longe das posturas dogmáticas e rígidas, distante da padronização dos indivíduos: um universo jurídico plural, flexível, eficiente.

Maria Berenice Dias, em inigualável argumentação, expôs:

As questões que dizem com a sexualidade sempre são cercadas de mitos e tabus, e os chamados desvios sexuais, tidos como uma afronta à moral e aos bons costumes, são alvo da mais profunda rejeição social. Tal conservadorismo acaba por inibir o próprio legislador de normar situações que fogem dos padrões aceitos pela sociedade. No entanto, fechar os olhos à realidade não vai fazê-la desaparecer, e a omissão legal acaba tão-só fomentando a discriminação e 0 preconceito. Estar à margem da lei não significa ser desprovido de direito, nem pode impedir a busca do seu reconhecimento na Justiça. Ainda quando o direito se encontre envolto em uma auréola de preconceito, o juiz não pode ter medo de fazer justiça. A função judicial é assegurar direitos, e não bani-los pelo simples fato de determinadas posturas se afastarem do que se convencionou chamar de normal ${ }^{13}$.

Seja a sexualidade o ponto de partida: quebrem-se tabus, reconsiderem-se limites. Seja o posto repensado, reanalisado, reinventado. Seja o direito, acima de tudo, questionado enquanto mecanismo de produção de verdades, a fim de que as mesmas não sejam ultrapassadas pelo real, pelo vivo, pelo humano.

Sejamos nós o motivo, a luta, a sensibilidade. Sejamos a consciência que, até então, se fez ausente. Sejamos diante do outro, pelo outro, com o outro. Sejamos, enfim, possibilidades.

\section{Referências}

ASÚA, Luiz Gimenez de. El criminalista. Buenos Aires: Editora La Ley, 1942.

\footnotetext{
${ }^{13}$ Idem, ibdem.
} 
ATAQUES de homofobia em São Paulo fizeram mais uma vítima no último sábado, 10/2. Disponível em: 〈http://www.acapa.com.br/site/noticia.asp?codigo=1135>. Acesso em: 24. Maio 2008

BENTO, Berenice. A reinvenção do corpo: sexualidade e gênero na experiência transexual. Rio de Janeiro: Gramind, 2006.

BRASIL. Constituição, 1988.

BRASIL. Tribunal de Justiça do Estado de São Paulo (5. Câmara). Civil. Apelação Cível no..165.157.4/5. Apelante: Adão Lucimar. Apelado: M inistério Público. Relator: Desembargador Boris Kauffmann. São Paulo, 22 de março de 2001.

BRASIL. Tribunal de Justiça do Rio Grande do Sul .Civil. Apelação Cível no 70018911594. Apelante: Ministério Público. Apelado: Sandro Márcio Eliodoro. Relator: Desembargador Sérgio Fernando de Vasconcelos. Guaíba, 25 de abril de 2007.

CONWAY, Lynn. Disponível em:http://ai.eecs.umich.edu/people/conway/TSsuccesses/ TSsuccesses-Portuguese.html. Acesso em: 20.maio.2008.

DIAS, M aria Berenice. Transexualidade e o direito de casar. Disponível em: http://www.uj.com.br/publicacoes/doutrinas/default.asp?action=doutrina\&iddoutrina.327. Acesso em: 15.junho.2008.

EVELYN, Just. Mom, I need to be a girl. Disponível em: http://ai.eecs.umich.edu/ people/ conway/TS/Evelyn/Portuguese/INTRO.PT.html. Acesso em: 19. maio. 2008

FOUCAULT, Michel. História da Sexualidade I - A vontade de Saber. Rio de Janeiro: Edições Graal, 1988.

GÂMBIA: Presidente diz que irá matar todos os homossexuais. Disponível em: http://mixbrasil.uol.com.br/mp/upload/noticia/11_101_66872.shtml. Acesso em: 24. maio. 2008

ONU, Declaração Universal dos Direitos do Homem, 1948.

PLATONOW, Vladimir. Sus começa esse ano inscrição para cirurgias de mudança de sexo. Disponível em: http://www.agenciabrasil.gov.br/noticias/2008/05/16/materia. 20080516.9449933138/ view. Acesso em: 24.maio.2008

PRECIADO, Beatriz. M anifiesto contra-sexual: práticas subversivas de identidade sexual. Madrid: Pensamiento Opera Prima, 2002. RESOLUÇÃO CFM no. 1.652/2002. Disponível em: বtttp://www.gendercare.com/ library/ cfmtrans.html>. Acesso em: 23 de abril de 2008. 
SUTTER, Matilde Josefina. Determinação e mudança de sexo. Aspectos médico-legais. São Paulo: Editora Revista dos Tribunais, 1993.

SZANIAWSKI, Elimar. Limites e possibilidades do direito de redesignação do estado sexual. Estudo sobre o transexualismo - aspectos médicos e jurídicos. São Paulo: Editora Revista dos Tribunais, 1998.

TRANSEXUAL consegue mudar registro sem cirurgia. Disponível em:

http://jus2.uol.com.br/pecas/texto.asp?id=847. Acesso em 24.maio.2008

TRANSEXUALIDADE. Disponível em http://pt.wikipedia.org/wiki/Transexual. Acesso em: 19. maio. 2008.

VIEIRA, Tereza Rodrigues. 0 Casamento entre Pessoas do mesmo Sexo no Direito Brasileiro e no Direito Comparado. Repertório IOB de Jurisprudência, n. 14/96, p. 255, jul. 1996. 